\title{
A MULHER, A CIDADE E O MURO: \\ O RECONHECIMENTO DO TRAÇO FEMININO NOS MUROS PELOTENSES
}

\section{Caroline Müller Antunes ${ }^{1}$}

Ana Paula Freitas Margarites ${ }^{2}$

\begin{abstract}
RESUMO: Este artigo traz como foco a discussão sobre a presença feminina no cenário do grafite e pichação, partindo da revisão de textos sobre escritas urbanas e estudo de caso das práticas de arte de rua produzidas por mulheres na cidade de Pelotas. A participação de mulheres no funcionamento das micropolíticas de ocupação do espaço urbano através do pixo e grafite são importantes ações de expressão, abrindo possibilidades que fomentam a discussão sobre gênero. $O$ estudo de caso ocorre na cidade de Pelotas/RS, especificamente no bairro Porto, ambiente universitário onde se constata atualmente um número bastante elevado de pichações de cunho feminista. Tais pichações evidenciam uma nova relação da mulher com a rua, e consequentemente com a cidade e a sociedade. Traços, vestígios e gritos, antes reprimidos, ressignificam e tornam visível a existência das mulheres no cotidiano da cidade.
\end{abstract}

PALAVRAS-CHAVE: feminismo; grafite; pixo.

\begin{abstract}
This article focuses on the discussion of the female presence in the graffiti scene, starting with a review of papers and dissertations on urban writing and a case study of street art practices produced by women in the city of Pelotas. The participation of women in the operation of micropolitics of occupation of the urban space through "pixo" and graffiti are important actions of expression, opening possibilities that foment the discussion about gender. The case study takes place in the city of Pelotas / RS, specifically in the Porto neighborhood, a university environment where a large number of feminist graffiti can be seen. Such graffiti brings up a new relation between women and the outdoors environment, consequently with the city and the society. Traces, vestiges and cries, previously repressed, resignify and make visible the existence of women in the daily life of the city.
\end{abstract}

KEYWORDS: feminism; graffiti; pixo.

\footnotetext{
${ }^{1}$ Graduanda do Bacharelado em Design do Instituto Federal Sul-Rio-Grandense eucarolantunes@gmail.com

${ }^{2}$ Professora do Bacharelado em Design do Instituto Federal Sul-Rio-Grandense; Mestra e Doutoranda em Educação - UFPel - anamargarites@gmail.com
} 


\section{INTRODUÇÃO}

O grafite, uma das mais presentes formas de inscrição urbana (LARA, 1998), tem sua aparição relacionada aos mais antigos registros gráficos feitos pelo ser humano. Desde os tempos mais remotos, o ser humano já se comunicava através de uma produção imagética registrada nas paredes das cavernas, onde apareceram as pinturas rupestres, bem como de outras formas de comunicação escrita (GITAHY, 1999). Talvez sejam estes os rabiscos iniciais do que entendemos hoje como arte e linguagem.

Na produção imagética desse contexto, as pinturas não eram produzidas a partir de um olhar que hoje relacionamos com o universo da arte; as imagens, naquele caso, tinham funções definidas (GOMBRICH, 2000). Para o homem primitivo, pintar as paredes não se justificava pela criação de algo belo para contemplação, mas pela criação de algo místico e poderoso, a criação de algo que "funciona" como mágica que reflete na realidade percebida. Em outras palavras, o pensamento dos caçadores primitivos era que, se fizessem uma imagem de sua presa sucumbida às suas lanças, os animais verdadeiros também sucumbiriam ao poder deles (GOMBRICH, 2000).

Nas civilizações mais antigas, como a dos egípcios, ocorria a narração de fatos em hieróglifos nas paredes dos túmulos dos faraós. Apesar de predominar a função decorativa e a aplicação de técnicas requintadas, pode-se distinguir e perceber relatos e mensagens que tinham como finalidade retratar os objetivos, os feitos e os cultos aos grandes líderes. (GITAHY, 1999)

$\mathrm{Na}$ contemporaneidade, considera-se que o aparecimento do grafite está ligado às manifestações em Paris em maio de 1968 (G1, 2017) com o uso de tinta spray, adaptado do uso da tinta sob pressão de uma bomba compressora, como na pintura automotiva (GITAHY, 1999). A partir do movimento de opressão política que resultou em rebeliões nas ruas européias, o grafite paulatinamente se espalhou para a América, sofrendo influências, nas décadas de 70 e 80 , dos movimentos hippie e punk (LARA, 1998). Desta maneira, buscando a liberdade de expressão de grupos antes silenciados, o grafite impõe-se tornando visível a contestação política e ideológica, dando voz a diferentes realidades.

Nas ruas de qualquer cidade no Brasil e no mundo, o grafite hoje torna-se visível através da aparição de marcas, rabiscos, ícones, logotipos e símbolos, que separados ou reunidos, compõem determinadas significações que se dispersam e se agrupam, 


\section{SULDESIGN CIENTÍFICO 2017}

VIII Suldesign - encontro sul-americano

formando grandes painéis que registram nomes, sobrenomes, palavras de ordem, de amor e humor, mensagens, letras, imagens, poemas e provérbios, entre outros, tornando visíveis segmentos sociais que podem vir a ser lidos por todos. Num tumulto de registros simbólicos e icônicos, vão pegando carona nos diferentes espaços urbanos, percorrendo a cidade e fazendo história.

No entanto, ao percorrermos a história do que está escrito nos espaços urbanos, vemos que boa parte destas inscrições não tem contado com a participação e a voz de metade da população mundial: as mulheres. Dia após dia, a mulher tem conquistado seu espaço e representação na sociedade atual, porém ainda são vários os nichos carentes de representatividade feminina, sendo ainda ambientes preconceituosos e hostis à participação da mulher. A arte de rua é um destes espaços: embora o universo acadêmico brasileiro tenha se ocupado recentemente em discutir a presença feminina no grafite (MATSUNAGA, 2006; HAMANN et al., 2013; SILVA, 2008), a existência de mulheres neste espaço ainda é um ato de resistência junto ao próprio universo em que buscam se inserir, de acordo com as autoras acima mencionadas.

Acredita-se que a participação de mulheres no funcionamento das micropolíticas de ocupação no espaço urbano da cidade, seja através do grafite, do pixo ou das colagens são importantes ações de expressão e intervenção, abrindo possibilidades a se fomentar a discussão sobre gênero, transformando o imaginário da rua a partir do olhar feminino, produzindo novas memórias e promovendo a aparição de novos modos de ser na cidade.

\section{GRAFITE $x$ PIXO}

O termo "grafite", em português, já foi uma expressão generalista utilizada para se falar sobre uma diversidade de inscrições urbanas; no entanto, com a consolidação da arte urbana, aparecem diversos termos distintos que falam sobre abordagens e técnicas diversas. Destacam-se os termos "grafite" e "pichação", mas identificam-se também outros termos como tag, throw-up, estêncil e lambe-lambe.

A pichação como conceito é um termo brasileiro designado para os escritos urbanos compostos por letras estilizadas, com poucas cores e de rápida reprodução, com enfoque ao ato - em geral tem um tom de protesto e de reconhecimento. Essa construção brasileira, de berço paulista, trata-se do pixo com " $x$ " (CHACON, 2014). 


\title{
SULDESIGN CIENTÍFICO 2017
}

VIII Suldesign - encontro sul-americano

O filme documentário Pixo (2009) fala sobre essa forma única de expressão na cidade de São Paulo, a partir de relatos de pichadores, fotógrafos e artistas sobre a experiência do Pixo e sua repercussão. Na fala do fotógrafo Choque (2009) estão as origens da pichação no Brasil:

A primeira pichação no Brasil é a pichação política contra a ditadura que começou na década de 60, que era o típico 'abaixo a ditadura' e onde o cunho era só político, não tinha a preocupação estética com as letras, era uma estética legível para qualquer alfabetizado ler. Depois da pichação da ditadura, que é a pichação política, vieram as pichações poéticas que como o próprio nome diz são frases poéticas. No começo da década de 80 , sendo um desdobramento do movimento punk, que também era pichação de cunho político, vem a pichação de São Paulo que é um pouco mais focado no ego no pichador. ( PIXO, 2009)

Entre os relatos presentes no filme, ficam claros os motivos que levam os pichadores a realizarem tais atos. Destacam-se: a "busca de adrenalina, reconhecimento, rebeldia, para que sejam visualizados nas ruas mais movimentadas da cidade; sempre fugindo da polícia e da ilegalidade dessa ação de protesto, afirmada na frase 'Arte como crime, crime como arte'” (HYPOLITO; ROCHA, p.2-3).

\begin{abstract}
O pichador adquire status de acordo com o local de aplicação do Pixo: existem aqueles que se utilizam de muros, janelas, prédios ou escaladas - o mais conceituado dentre as categorias - e aqueles que fazem todos os tipos; o que importa é a quantidade; quanto mais letreiros existirem na cidade, com o logo de uma crew3 ou do próprio pichador, mais reconhecimento haverá (HYPOLITO; ROCHA, pg. 2-3, 2013).
\end{abstract}

\section{A MULHER E O MURO}

De acordo com Hypolito e Rocha (2013), a produção da arte urbana modifica a vivência cotidiana do sujeito com a cidade que habita, aumentando as possibilidades da relação entre corpo e cidade, produzindo novos sentidos, participando no processo de construção de sujeitos e na produção de suas subjetividades; "construindo uma cidade sempre em devir" (FURTADO, 2009, p.1290 apud HYPOLITO; ROCHA, 2013), um

\footnotetext{
${ }^{3}$ Entende-se por "crew" um grupo de amigos que habitualmente pintam juntos e que utilizam todos o mesmo nome. É regra geral os pichadores assinarem o seu tag e respectiva crew.
} 


\title{
SULDESIGN CIENTÍFICO 2017
}

VIII Suldesign - encontro sul-americano

constante vir a ser. Pensa-se a intervenção urbana como maneiras de vir a ser tanto do ser humano como da cidade.

\begin{abstract}
O grafite e a pichação criticam a estrutura da cidade, suas territorialidades, suas regulamentações, seus espaços definidos de expressão, comunicação e diálogo, e constituem linhas de fuga e resistência dentro das propostas padronizadas, funcionais e restritivas de organização urbana. (FURTADO, 1994, p.1294 apud HYPOLITO; ROCHA, 2013)
\end{abstract}

Em sua pesquisa de campo na zona portuária de Pelotas, Hypolito e Rocha (2013) trazem os transbordamentos da pichação em Pelotas. Através de levantamento fotográfico, a autora percebeu a intensidade dessas manifestações em muros abandonados, equipamentos urbanos e fachadas privadas, que vão desde a pichação de cunho poético, passando pelas de cunho político e letreiros com as logos das crews até o grafite de desenhos dos mais diversos. As escritas de cunho poético enaltecem a beleza da sociedade e das potências de se viver em comunidade, enquanto as de cunho político alertam para a miséria, a diferença social instaurada, o crime e os movimentos político e sociais.

Silva (2008), em sua pesquisa, traz a identidade da mulher na prática do grafite, analisando a formação de identidade social das grafiteiras de Porto Alegre. A autora identifica essas mulheres como escritoras de rua que imprimem nos muros uma prática de construção de identidade, como mulheres conquistando espaço em um território até então predominantemente masculino - o "mundo" do grafite e do hip hop.

No estudo "Meninas do grafite: Adolescência, Identidade e Gênero nas Culturas Juvenis Contemporâneas", Magro (2003) identifica que a presença de meninas envolvidas no movimento, visto ser em um universo predominantemente masculino, ainda é bastante tímida, embora essas grafiteiras procurem uma certa articulação em projetos sociais e oficinas.

Experiência de meninas que transgridem, ocupam o espaço fincado pela bandeira do macho, tentam construir outros corpos de mulher no espaço urbano de periferia, estruturado e cristalizado naturalmente - mas como possibilidade estratégica de reivindicar um lugar no mundo, ser reconhecida como ser que se expressa, cria, vivencia em seus sentidos, modula sua própria voz - seja aguda, dissonante ou desafinada. Elas marcam presença nas ruas, pelas cores que são grafitadas nos muros, e que revelam a elas próprias suas identidades no 


\section{SULDESIGN CIENTÍFICO 2017}

VIII Suldesign - encontro sul-americano

transitar pelo espaço público, mostrando a existência vivida, do preto-e-branco às cores (MAGRO, 2004, p.109).

Silva (2008) reforça que ainda há muito a ser investigado sobre a inserção das mulheres nas práticas de rua. $O$ universo da grafitagem serve de instrumento do qual as mulheres se utilizam para se expressar e formar identidades, o que pode, consequentemente, promover um debate sobre conceitos e relações de gênero e subjetividade.

Esta manifestação artística, quando praticada pelas mulheres, pode ser relacionada à emergência de novos movimentos sociais, inclusive com a participação feminina e à sua luta por direitos de cidadania, favorecendo o aparecimento de novas formas de inserção social. Da mesma forma como a dança, a música, a expressão visual do hip hop, o grafite, auxilia na expressão de sentimentos, de experiências que podem levar algumas mulheres grafiteiras a criarem grupos femininos de grafite, redefinindo identidades de gênero onde os estereótipos acerca do feminino já não cabem.

\section{O QUE ELAS ESTÃO COLOCANDO NOS MUROS?}

Entre as questões que a pichação feita por mulheres nos coloca, estão: O que elas estão querendo dizer com o que fazem? São intervenções para serem apreciadas ou realmente para causar o incômodo? Como essas ações atingem as pessoas? Afinal, o que pixo e grafite (e das outras intervenções urbanas) provocam as pessoas e como isso pode ser importante na representação e na produção de novos modos de ser do feminino?

Questiona-se se as mulheres possuem as mesmas condições de acesso que os homens nestes movimentos urbanos, visto que ainda há uma evidente assimetria de papéis e de poder. Até o momento não foi identificada nenhuma pesquisa sobre o processo de inserção da mulher nessa expressão em Pelotas, o que prova a importância social de debater esse tema.

Uma hipótese levantada em relação à menor participação feminina nas escritas urbanas pode vir a ser justificada pelo menor tempo que as mulheres tendem a passar na rua. É evidente a preocupação com o horário de se estar na rua, o que identifica-se como muito comum no meio feminino, por questões de segurança, padrões sociais, etc. 


\section{SULDESIGN CIENTÍFICO 2017}

VIII Suldesign - encontro sul-americano

Discussões sobre a ocupação do espaço público predominantemente por homens estão presentes na epistemologia feminista há bastante tempo, como nos escritos de Perrot $(1993,2011)$. Em seu capítulo sobre os quartos femininos no livro História dos Quartos, Perrot afirma:

Tudo concorre para encerrá-las aí: a religião, a ordem doméstica, a moral, a decência, o pudor, mas também o imaginário erótico, que senta as mulheres sonhadoras à janela ou as reclina, leitoras lânguidas, mais ou menos despidas sobre um sofá ou um canapé ou uma cama. (PERROT, 2011, p. 13)

A dicotomia entre público e privado é também colocada por Sofia Aboim para discutir a presença feminina na arte de rua, relacionando os conceitos valorativos investidos à pichação e ao grafite. As diferenciações entre as expectativas de gênero, conceituadas sob a ótica reducionista do binarismo, são intimamente relacionadas, nas narrativas, à dicotomia entre público - esfera política, destinada tradicionalmente aos homens - e privado - esfera doméstica, que relaciona a mulher à maternidade e ao lar -, determinando uma hierarquia do masculino sobre o feminino (Aboim, 2012 apud HAMANN, 2016)

Dentro do universo do grafite pelotense, tem-se percebido maior envolvimento das mulheres com a linguagem da pichação, colocada como uma forma de expressão de caráter transgressor, normalmente de cunho político e de lutas relacionadas ao feminismo.

Em caminhadas pelo centro histórico e pela zona portuária de Pelotas, percebese frases de cunho político e poético ligados ao feminismo; frases, tags e escritos diversos (Figuras 01, 02, 03); desenhos do símbolo feminino (Figura 05); representações de vaginas e coletores menstruais (Figura 04).

Figura 01 - "Aborto Livre!" 


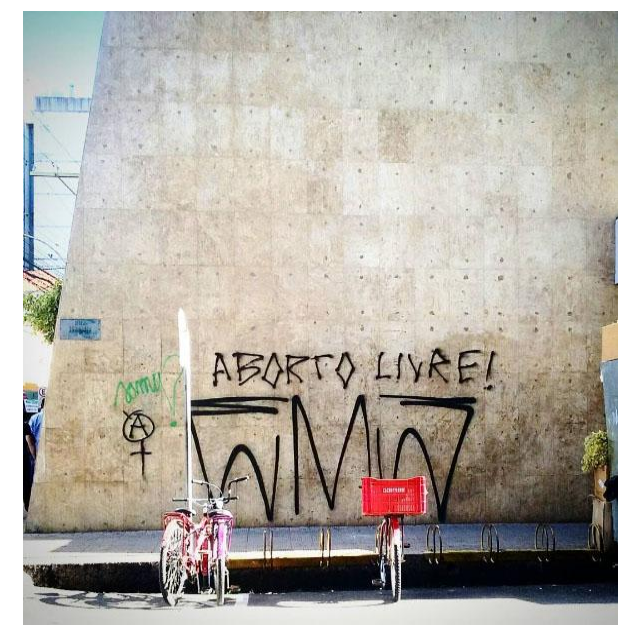

Fonte: Fotografia da autora

Figura 02 - "Empodere otra mina!"

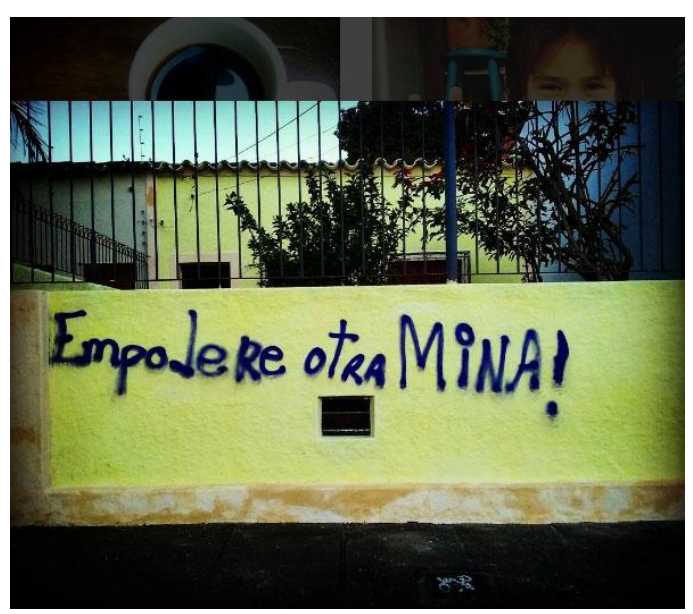

Fonte: Fotografia da autora

Figura 03 - "Estupro não é referência artística"

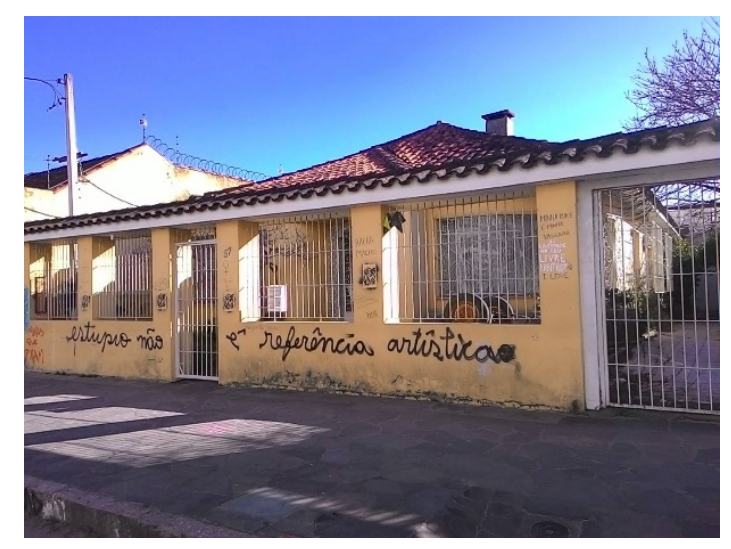

Fonte: Fotografia da autora 


\section{SULDESIGN CIENTÍFICO 2017}

VIII Suldesign - encontro sul-americano

Figura 04 - Coletor menstrual e "Se toca"

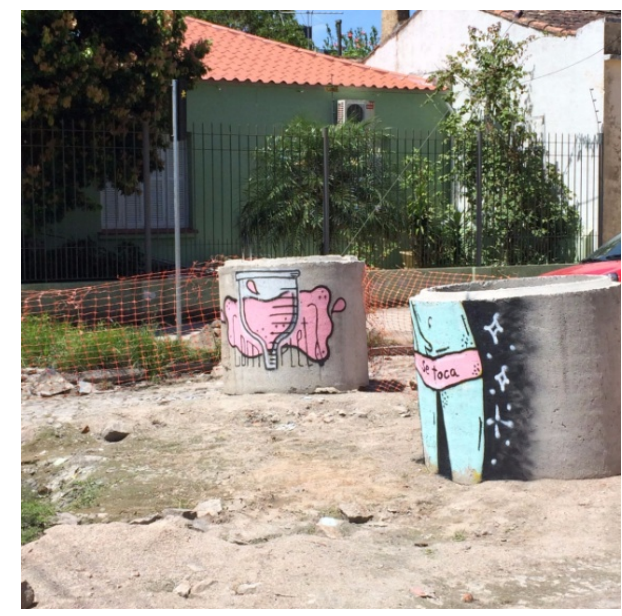

Fonte: Fotografia da autora

Figura 05 - "minas nas alturas"

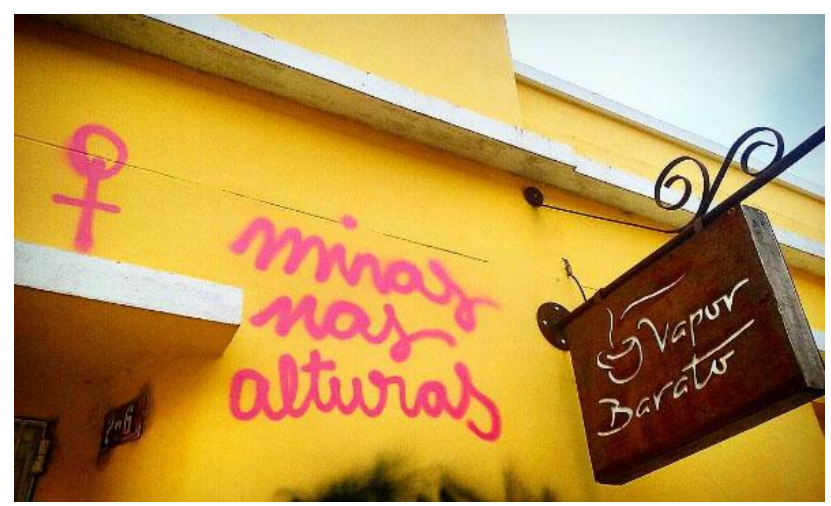

Fonte: Fotografia da autora

Entre as frases que lemos na zona portuária de Pelotas, destacamos: "O pixo é a voz das ruas"; "Se liga nas mina"; "As mina se juntou"; "Empodere otra mina"; "Vocês vão nos engolir até engasgar"; "XXT Power"; "Aborto Livre"; "Estupro não é referência artística!"; "Não passo beck pra machista"; "Botei meus demônios pra dançar"; "A revolução vai ser das mina \#asminaéopoder blackpower"; "Feminismo é revolução"; "Minas que pixam"; "Crew das mina"; "Minas nas alturas".

Ainda que as pichações feministas passem por um momento efervescente na cidade de Pelotas, identificam-se ainda poucas mulheres intervindo na rua de forma reconhecida em comparação com os exemplos masculinos já consagrados na cidade. Verifica-se que enquanto homens mantêm-se mais estáveis nos grupos de pichação, sobrepondo esta prática inclusive às noções de paternidade, foi relatado pelas 


\section{SULDESIGN CIENTÍFICO 2017}

VIII Suldesign - encontro sul-americano

mulheres, em entrevistas, um afastamento temporário da prática da pichação por questões relativas à maternidade e ao lar. O plano privado, dessa forma, divide espaço com o plano público para elas, muitas vezes sobressaindo-se. Enquanto isso, para os homens pichadores, o plano público sempre prevalece, retomando a divisão binária tradicional e logrando reconhecimento por parte das comunidades de praticantes (HAMANN, 2016).

Dentro do grafite artístico, visualmente agradável e aceitável como intervenção urbana, não identifica-se representação estável de mulheres na técnica em Pelotas. Nas conversas com mulheres pichadoras e grafiteiras, percebe-se que as poucas que em algum momento se arriscaram a começar a pintar, com o tempo reduziram ou mesmo abandonaram a prática. Percebeu-se que várias começam por influência de amigos próximos, namorados, mas por algum motivo não se motivaram a continuar. Várias das artistas entrevistadas consideraram que isso acontece por não existir uma força coletiva de mulheres no meio do grafite, e acredita-se também que a descontinuidade da prática pode estar ligada à sensação de insegurança causada pela permanência mais extensa na rua, necessária na execução de pinturas mais complexas.

\section{CONSIDERAÇÕES FINAIS}

Percebe-se, no centro e na zona portuária da cidade de Pelotas, um crescimento considerável na aparição de pichações produzidas por mulheres. Tais artistas que se colocam na rua parecem se identificar mais com a linguagem do pixo, por razões que supomos estarem ligadas ao domínio masculino no universo do grafite dito "artístico" e à percepção da pichação como forma de expressão mais relacionada a questões políticas de resistência.

Foi possível perceber que existem relações entre os papéis tradicionais de gênero na ocupação visual do espaço urbano, relacionadas à dicotomia entre o público e o privado e sua ocupação tradicionalmente colocada por homens e mulheres. A inserção de mulheres nas atividades de transgressão ocorreu vezes devido à aproximação da arte urbana promovida por seus cônjuges ou amigos, porém mais fortemente de forma autônoma, especificamente no caso de Pelotas, como forma de expressão de protesto e palavras de ordem feministas e empoderadoras. 


\section{SULDESIGN CIENTÍFICO 2017}

VIII Suldesign - encontro sul-americano

Acredita-se que o ambiente da hostil da rua, antes dominado e significado por homens, tem sofrido uma reescritura por parte das mulheres que não aceitam mais o papel único de privado, quebrando o paradigma da sociedade em ficar do lado de dentro do muro, ultrapassando-o como barreira a ser deixada no passado, expressando sua resistência nos muros e reescrevendo o ambiente urbano. 


\section{REFERÊNCIAS}

CHACON, Theo. Traços urbanos: pixo e grafite entre a Indústria Cultural e o preconceito. 2014. Revista Vaidapé. Disponível em: <http://vaidape.com.br/ 2014/05/tracos-urbanos-pixo-e-grafite-entre-a-industria-cultural-e-o-preconceito/>.

Acesso em: 12 mar. 2017.

FURTADO, Janaína; ZANELLA Andréia Vieira. grafite e cidade: sentidos da intervenção urbana e o processo de constituição dos sujeitos, Rev. Mal-Estar Subj. vol.9 no.4 Fortaleza dez. 2009.

G1. Conheça 68 das frases mais marcantes de maio de 68. Disponível em: < http://g1.globo.com/Sites/Especiais/Noticias/0,,MUL463636-15530,00-

CONHECA+DAS+FRASES+MAIS+MARCANTES+DE+MAIO+DE.html >. Acesso em: 02 de mar. 2017.

GITAHY, C. O que é grafitti. Editora Brasiliense. São Paulo, S.P. 1999.

GOMBRICH, Ernst. A História da Arte. 16ª edição. Rio de Janeiro: LTC, 2000.

HAMANN, Cristiano; CARDOSO, João G. M.; TEDESCO, Pedro de C. e PIZZINATO, Adolfo. Entre o público e o privado: discurso de mulheres em movimentos de grafite. Ex aequo [online]. 2013, n.28, pp.45-58. ISSN 0874-5560. Disponível em $<$ http://www.scielo.mec.pt/scielo.php?pid=S0874-

55602013000200005\&script=sci_arttext\&tlng=p> Acesso em: 28 jul. 2016.

HYPOLITO, Bárbara de Bárbara; ROCHA, Eduardo. Escritas Urbanas - Vozes Silenciadas. In.: III Seminário Integrador Escrileituras, 2013. Anais do III Seminário Integrador Escrileituras: UFPel, 2013. Disponível em: <http://modosdelerescrever .ufpel.edu.br/anais/pdf/BARBARADEBARBARAHYPOLITO.pdf>. Acesso em: 28 jul. 2016. 


\section{SULDESIGN CIENTÍFICO 2017}

VIII Suldesign - encontro sul-americano

LARA, Arthur Hunold. Grafite: arte urbana em movimento. 1996. 169 f. Dissertação (Mestrado) - Progama de Pós-Graduação em Artes Visuais, Universidade de São Paulo, São Paulo - SP, 1996.

MATSUNAGA, Priscila. Mulheres no hip hop: identidades e representações. 2006. 209 f. Dissertação (Mestrado) - Universidade Federal de Campinas, Campinas - SP 2006.

PERROT, Michelle. História dos Quartos. São Paulo, Paz e Terra, 2011.

PERROT, Michelle (org). História da vida Privada 4: da revolução francesa à primeira guerra. São Paulo, Companhia das Letras, 1993.

PIXO. Direção: João Wainer e Roberto T. Oliveira. São Paulo: Sindicato Paralelo Filmes, 2009. (61 min.), widescreen, color., legendado.

SILVA, Vívian. As escritoras de grafite de porto alegre: Um estudo sobre as possibilidades de formação de identidade através dessa arte. 113f. Dissertação (Mestrado em Ciências Sociais) Faculdade de Ciências Sociais, Universidade Federal de Pelotas, Pelotas, 2008. 